\title{
Morale of vocational dental practitioners in the United Kingdom
}

\author{
J. Gilmour ${ }^{1}$ and D. A. Stewardson ${ }^{2}$
}

IN BRIEF

- Provides a measure of morale among VDPs throughout the UK.

- Universal concern was evident regarding future changes in the NHS, the limits on treatment within the current NHS system and earning enough.

- English and Welsh VDPs were worried about being able to work in the locality and a practice that they liked.

- Continued monitoring of changes in morale is possible using this survey instrument.

Objective This study was undertaken to devise a suitable survey instrument to measure morale, and to undertake an assessment of morale amongst vocational dental practitioners (VDPs) in the UK. Design Postal questionnaire survey. Setting Dental vocational training schemes in the UK. Subjects Vocational dental practitioners. Method A confidential postal questionnaire was used to measure levels of morale among all VDPs in the UK in 2007. Results A response rate of 76.7\% was achieved. The mean morale score for Scottish VDPs was significantly higher than that of the Northern Irish VDPs, which in turn was significantly higher than those of the VDPs in England or Wales. In England and Wales females recorded higher morale scores than males. Lowest morale scores were associated with statements referring to concerns about future changes to NHS dentistry, and the limits on treatment within the NHS system. The highest scores were associated with good working relationships. Conclusion The use of an appropriately tested questionnaire has provided a convenient objective measure of morale. The morale of VDPs in the United Kingdom was lower than expected. Scottish VDPs recorded higher morale scores than other VDPs and responded more positively in the survey instrument. The most negative responses from all VDPs were regarding the effect of the NHS system on treatment and concerns about future changes to the NHS.

\section{INTRODUCTION}

Morale, as defined by the Oxford English Dictionary, ${ }^{1}$ is the mental or emotional state (with regard to confidence, hope, enthusiasm, etc) of a person or group engaged in some activity: degree of contentment with one's lot or situation. Interest in morale follows from the appreciation that discontent amongst members of a group directly affects the functioning of that group. Therefore, if morale within

'General Dental Practitioner, 27 High Street, Chasetown, Burntwood, Staffs, WS7 3XE; ${ }^{2 *}$ Lecturer in Conservative Dentistry, University of Birmingham, School of Dentistry, St Chad's Queensway, Birmingham B4 6NN ${ }^{*}$ Correspondence to: Mr Dominic A. Stewardson Email:d.a.stewardson@bham.ac.uk

\section{Online article number E18}

Refereed Paper - accepted 28 January 2008

DOI: $10.1038 /$ sj.bdj.2008.401

${ }^{\oplus}$ British Dental Journal 2008; 204: E18 an organisation is low, the organisation as a whole will suffer. Studies of morale within a variety of organisations $\mathrm{s}^{2-4}$ have identified a number of common effects resulting from low morale, namely: low productivity and levels of achievement, reduced quality of output, increased turnover and absenteeism of staff. ${ }^{5-6}$ The National Health Service (NHS) has recognised that high staff morale improves patients' experience, and has declared that 'improving staff morale is the third principle by which the NHS is becoming a model employer'? In the medical field, studies of morale among doctors have been undertaken to look at changes over time, and under different payment regimes. ${ }^{8-12}$ Within dentistry, job satisfaction has been examined as well as the nature and effects of stress on dentists, ${ }^{13-}$ ${ }^{16}$ but the level of contentment with the organisation has received little attention.
In April 2006 the UK government implemented major changes in the way in which NHS dentistry was provided and funded in England and Wales. ${ }^{17}$ Practitioners were obliged to negotiate new contracts with their Primary Care Trusts (PCTs) or Local Health Boards defining the amount of treatment which would be carried out in units of dental activity (UDAs) and the value of the contract to the dentist. As the new system came into force, the majority of dentists had signed new contracts 'in dispute'. Before these changes, newly qualified dentists in their pre-registration year as vocational dental practitioners (VDPs) were free to continue working at their training practice or to move to any other practice where a vacancy was available. Now, the PCTs which act as purchasers of primary dental services control the number and location of NHS dental practices in their area and 
the number of dentists in those practices, via the new contract arrangements. This can compel new dentists to move away from friends and family if they wish to work in an NHS practice. Such pressures are likely to increase stress, affect job satisfaction and lower morale.

To evaluate staff morale, some means of monitoring and measurement is necessary. The objective measurement of any psychological or emotional state presents significant challenges in the absence of physical manifestations of that condition. The approach adopted by many investigators has been to look for the presence of indicators of low or high morale in the attitudes and feelings of individuals. ${ }^{9,18}$ Each has devised a questionnaire or series of questionnaires to explore the extent and degree of negative attitudes reported. Previous work has found that low morale is associated with: lack of commitment or loyalty to the organisation, reduced job satisfaction and feelings of being undervalued, under rewarded and overworked, receiving insufficient respect and having a low sense of fulfilment, and a perceived lack of professional advancement or career development. ${ }^{2,19,20}$ For this study, the authors looked at commercial morale survey instruments for use in businesses, and those created for use with medical practitioners and other professions, but none related well to the work situation of dental practitioners. It was therefore decided to devise a questionnaire which would relate the common indicators and effects of low morale in a format pertinent to VDPs.

From the results of morale studies conducted in other fields, discontent among VDPs could result in a reduction in the quality of patient care, and lead to dentists leaving the NHS or perhaps leaving the profession entirely. At this time of major change within NHS dentistry, morale among dentists is of great importance. The aims of this study therefore were to establish a suitable survey instrument to measure morale, and to undertake a comparative assessment of morale amongst VDPs across the UK.

\section{METHOD}

A questionnaire was devised consisting of 20 statements with which respondents

Table 1 Gender and ages of the VDP respondents

\begin{tabular}{l|l|l|l}
\multirow{2}{*}{} & Age & Sex \\
\cline { 2 - 4 } & Mean (SD) & Female (\%) & Male (\%) \\
\hline ALL & $25(2.79)$ & $365(57.2 \%)$ & $273(42.8 \%)$ \\
\hline England & $24.9(2.58)$ & $208(58.5 \%)$ & $199(41.5 \%)$ \\
\hline Wales & $25.6(3.15)$ & $24(51.1 \%)$ & $23(48.9 \%)$ \\
\hline Scotland & $24.9(3.8)$ & $49(55.7 \%)$ & $39(44.3 \%)$ \\
\hline N. Ireland & $24.6(1.1)$ & $12(50 \%)$ & $12(50 \%)$
\end{tabular}

Table 2 Mean (standard deviation), maximum and minimum morale scores for all respondents, and from each of the four national regions

\begin{tabular}{|l|l|l|l} 
& Mean \% Score (SD) & Max & Min \\
\hline ALL & $43.76(12.86)$ & 88.9 & 6.9 \\
\hline England & $41.35(11.43)$ & 73.6 & 6.9 \\
\hline Wales & $41.72(12.47)$ & 68.1 & 12.5 \\
\hline Scotland & $56.77(13.31)$ & 88.9 & 20.8 \\
\hline N. Ireland & $48.2(9.47)$ & 63.9 & 19.4
\end{tabular}

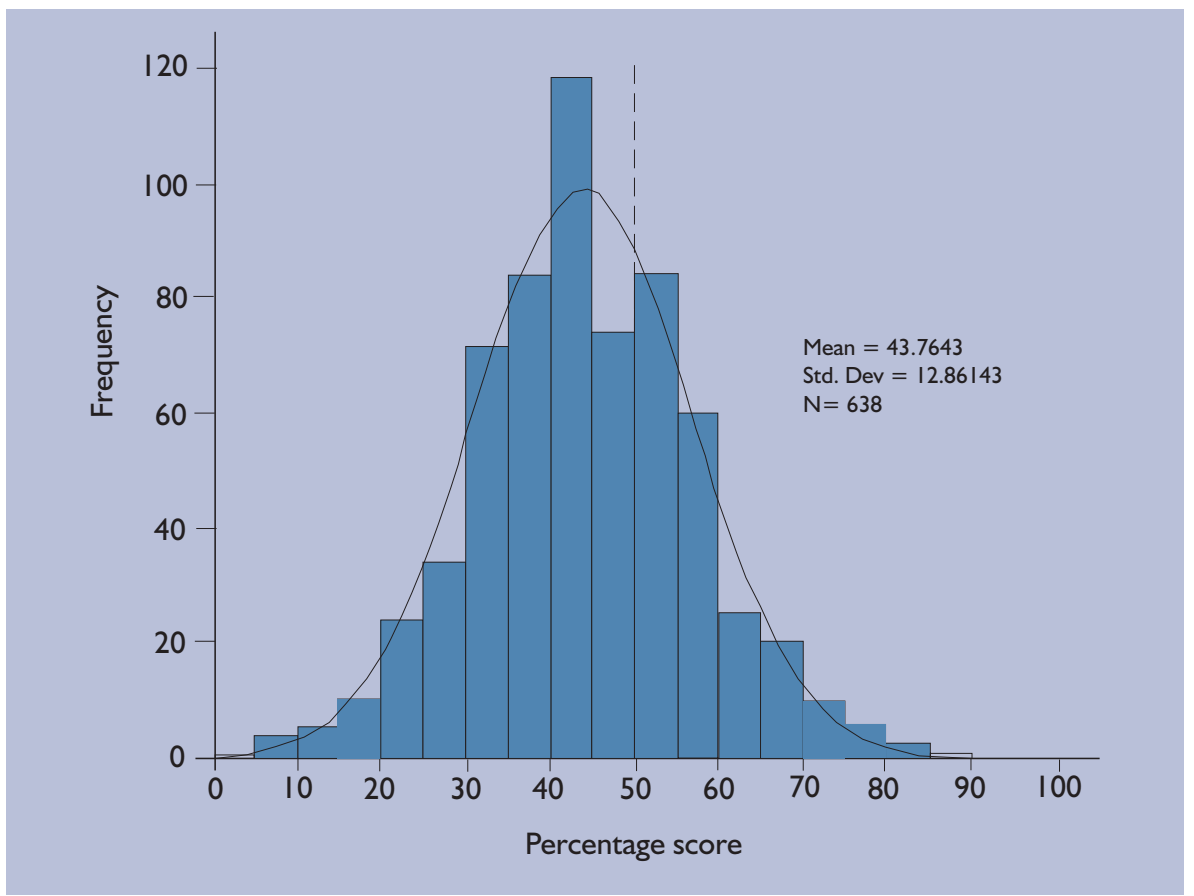

Fig. 1 Histogram showing distribution of mean percentage morale scores for all UK VDPs

could indicate their level of agreement on a 5-point Likert scale from 'strongly agree' to 'strongly disagree'. These were intended to reflect the common indicators and effects of low morale in dentally relevant terms. The wording of the statements was varied so that, for half of the statements, strong agreement indicated low morale while in others strong agreement would signal high morale. In addition, there was a section which recorded the sex, age, dental school and vocational training scheme of the respondent, and the number of dentists in their practice. At the end of the form, respondents were asked to add any further comments of their own. The Likert responses were scored from 1 = strong agreement (and low morale) to $5=$ strong disagreement, with reverse scoring as appropriate to the wording of the statements. An overall score for morale could then be obtained. The questionnaire was piloted among 20 VDPs in two groups from the West 


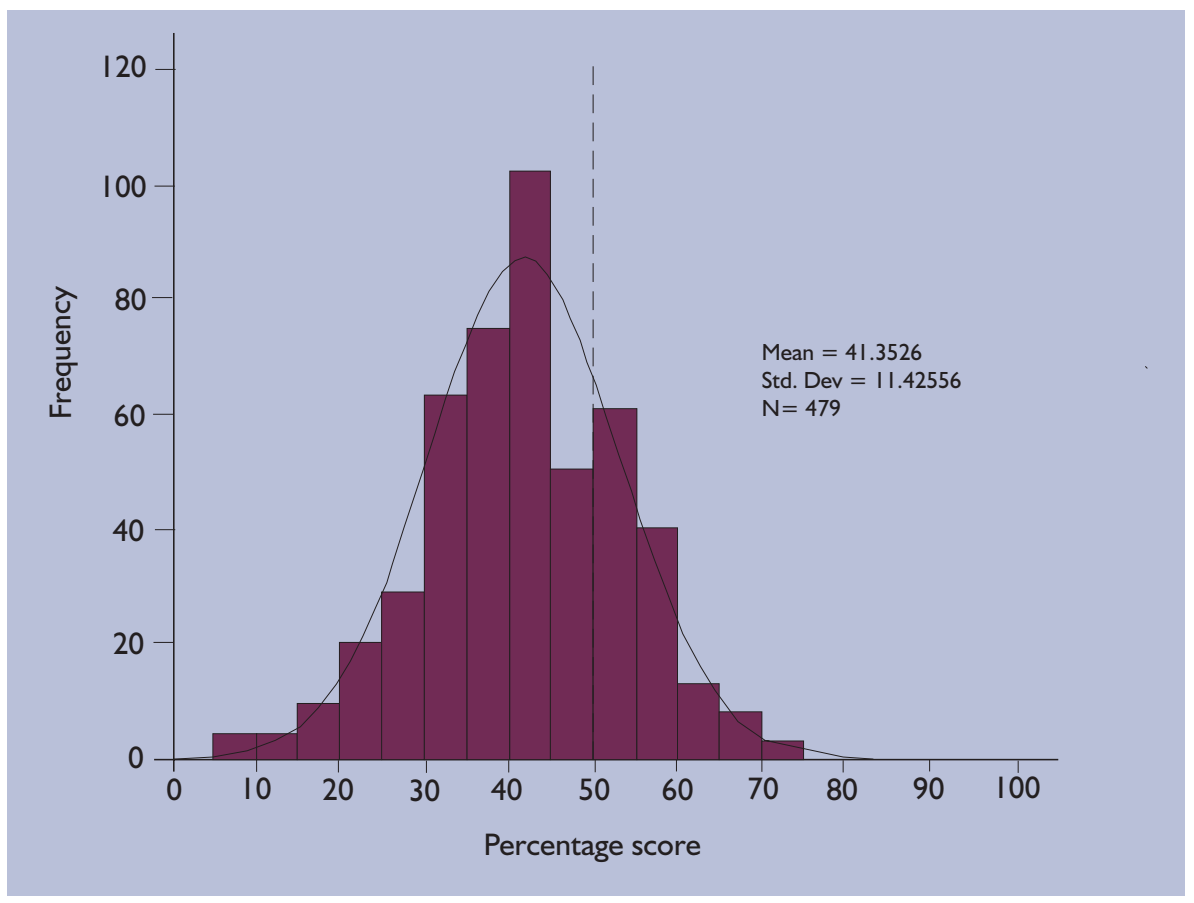

Fig. 2 Histogram showing distribution of mean percentage morale scores for VDPs in England

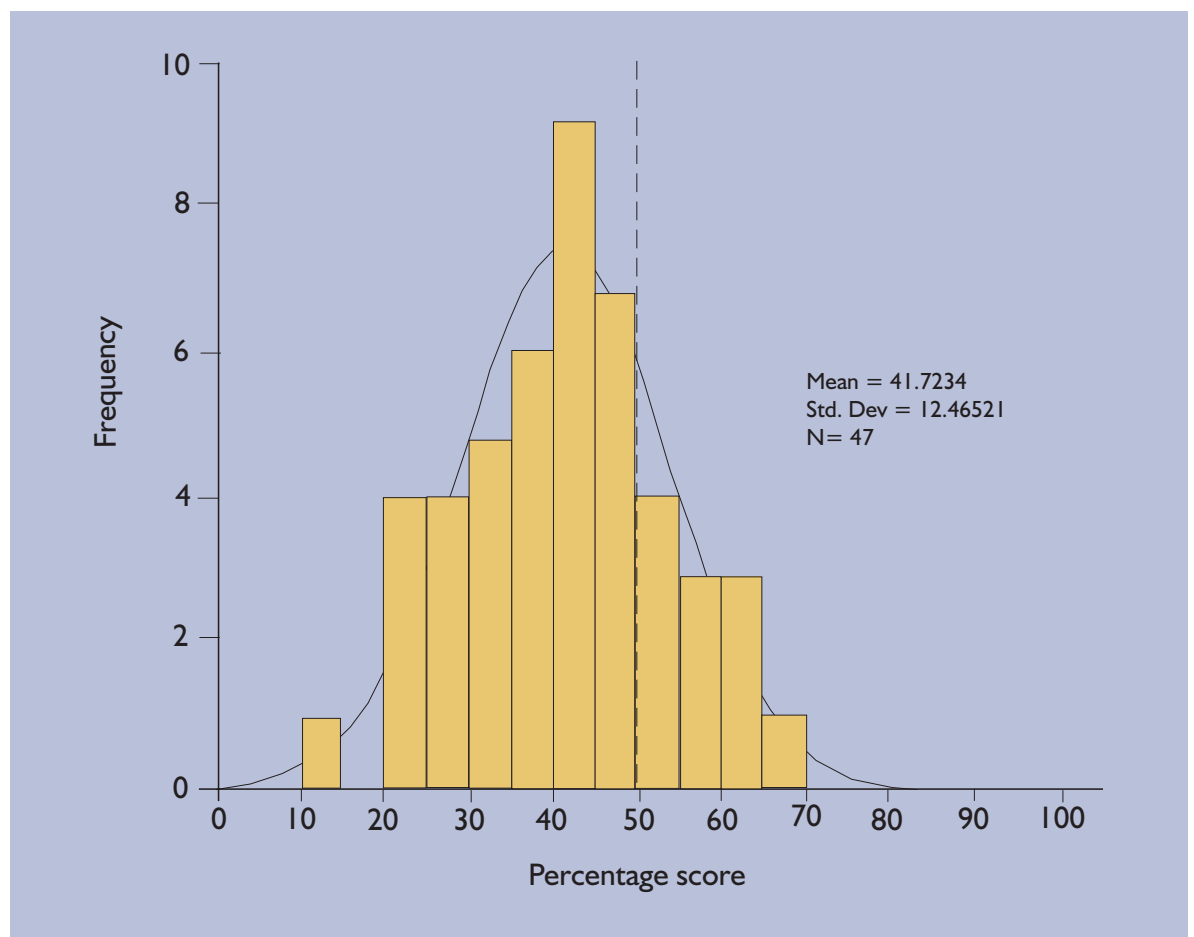

Fig. 3 Histogram showing distribution of mean percentage morale scores for VDPs in Wales

Midlands and the South West of England. In this phase, comments and suggestions on clarity and content of the questionnaire were invited. From the comments received, the questionnaire appeared to have good face validity. To assess internal validity, the average inter-item correlation was assessed using Cronbach's alpha. ${ }^{21}$ For the 20 statements the overall alpha value was 0.56 which is below the level considered acceptable for a reliable survey instrument. By removing two collecting the questionnaires amongst their VDPs (Appendix 1). Each questionnaire included a covering letter to the VDP outlining the importance of the project, requesting that they complete the questionnaire and ensuring them that their replies would be non-attributable. These were distributed to the VDPs at one of their regular training days by the VT adviser and, to ensure anonymity, it was recommended that they were collected by one of the group who sealed them in a stamped addressed envelope for return to the investigators. With the exception of the three mid-year schemes, this was carried out within the three months prior to completing their VT training to give sufficient time for completion of the survey, but close enough to the end of their training year when they would be considering their move to full independence. As a comparison cohort, VDPs in Scotland and Northern Ireland were similarly surveyed. As no such changes in payment and working arrangements had occurred in these regions, it could be possible to assess the effects of the changes introduced in England and Wales on morale. The scores for morale and the demographic information were entered into a database for analysis using the statistical package SPSS V12 (SPSS Inc. Chicago USA) with a significance level set at $\mathrm{p}=0.05$.

\section{RESULTS}

Within the survey period, there were 862 VDPs undergoing training in the UK from whom 661 replies were received, a response rate of $76.7 \%$. Twenty-three questionnaires were rejected as they were incomplete giving an effective response rate of $74 \%$.

The numbers and response rates from each of the four national regions of the UK were Scotland 88 (67.7\%), Northern Ireland 24 (100\%), England 479 (74.6\%) and Wales 47 (71\%). The demographic details shown in Table 1 indicate that overall there are more female VDPs than males, although the proportions are similar in each region. The mean scores for morale for each region are shown in Table 2.

Histograms showing the distribution of percentage morale scores from the respondents within the four regions are shown in Figures 1-5 and indicate that 
Table 3 Mean percentage morale scores of VDPs from each dental school. Statistically homogeneous subsets indicated by letters

\begin{tabular}{|l|l|l|}
\hline Dental School & Number & Mean score \\
\hline Glasgow & 45 & $59.14 a$ \\
\hline Dundee & 33 & $52.52 \mathrm{ab}$ \\
\hline Belfast & 34 & $49.67 \mathrm{abc}$ \\
\hline Leeds & 39 & $45.8 \mathrm{abc}$ \\
\hline Non-E.U. & 25 & $44.44 \mathrm{bc}$ \\
\hline Newcastle & 55 & $44.37 \mathrm{bc}$ \\
\hline Sheffield & 37 & $44.26 \mathrm{bc}$ \\
\hline Bristol & 42 & $43.48 \mathrm{bc}$ \\
\hline E.U. & 13 & $41.99 \mathrm{bc}$ \\
\hline OMU & 42 & $41.9 \mathrm{bc}$ \\
\hline Cardiff & 36 & $40.08 \mathrm{bc}$ \\
\hline KCL & 111 & $39.99 \mathrm{bc}$ \\
\hline Liverpool & 25 & $39.84 \mathrm{bc}$ \\
\hline Manchester & 49 & $38.8 \mathrm{bc}$ \\
\hline Birmingham & 52 & $37.55 \mathrm{c}$ \\
\hline
\end{tabular}

among the majority of respondents the mean morale score was below 50\% with the exception of Scottish VDPs where the mean score was $56.8 \%$. The data were analysed to identify for any statistically significant differences in the mean morale scores associated with the factors of country, sex, dental school or age $(p=0.05)$. One-way Anova with post hoc Scheffé tests identified no difference between the morale scores of VDPs in England and VDPs in Wales, but the mean score for Scottish VDPs was significantly higher than the score of the Northern Irish VDPs, which in turn was significantly higher than those of the VDPs in England or Wales ( $p<0.05$ ). Independent sample T-tests showed that the morale score for females was significantly higher than that of males in England ( $p=0.038$ ) and Wales ( $p=0.026)$, but there was no significant difference between the sexes in Scotland or Northern Ireland ( $p$ >0.05).

Comparing dental schools using oneway Anova showed some statistically significant differences in the morale scores, which mirror the regional differences already identified (Table 3). It was also observed that the majority of the VDPs within each country's

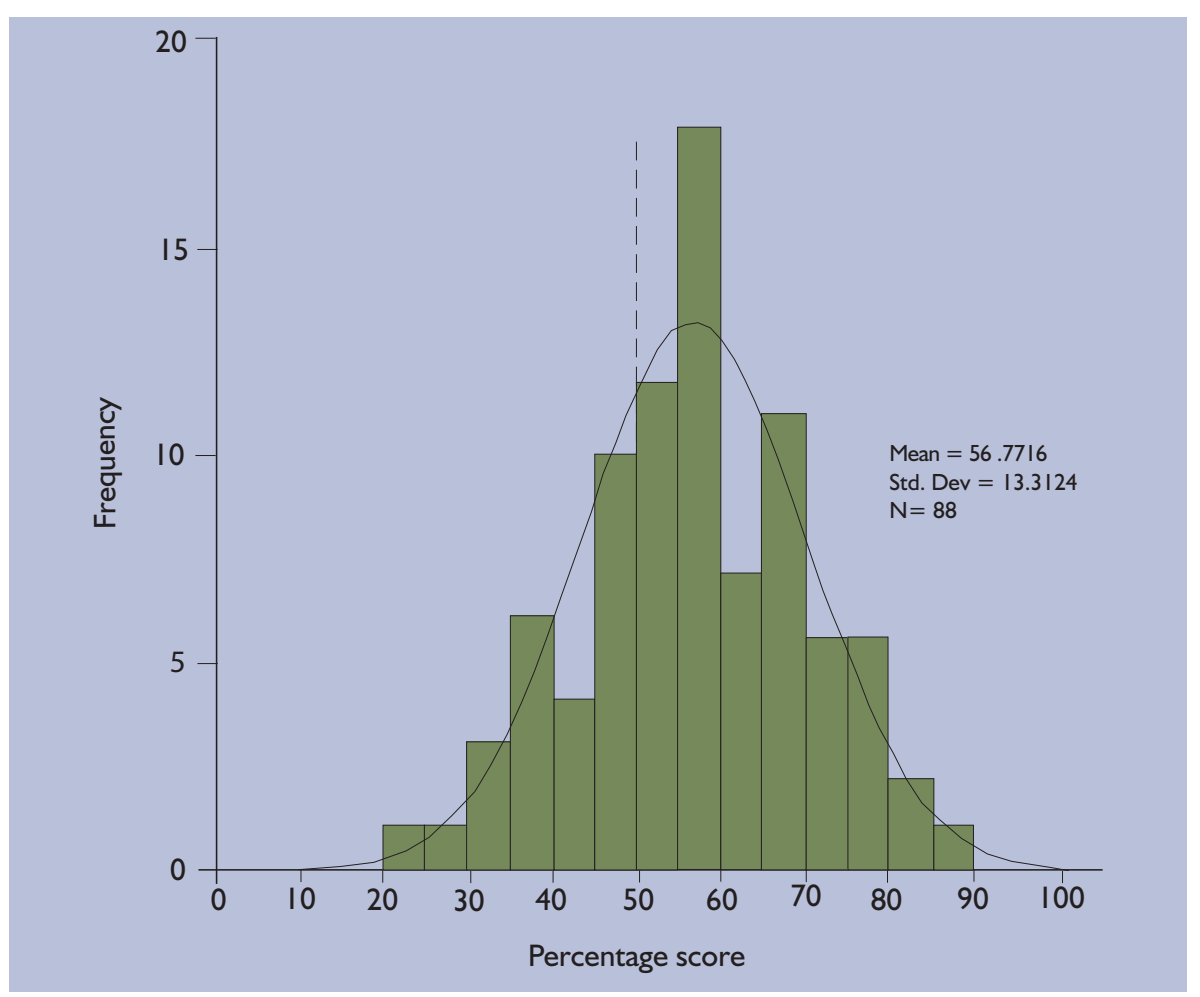

Fig. 4 Histogram showing distribution of mean percentage morale scores for Scottish VDPs

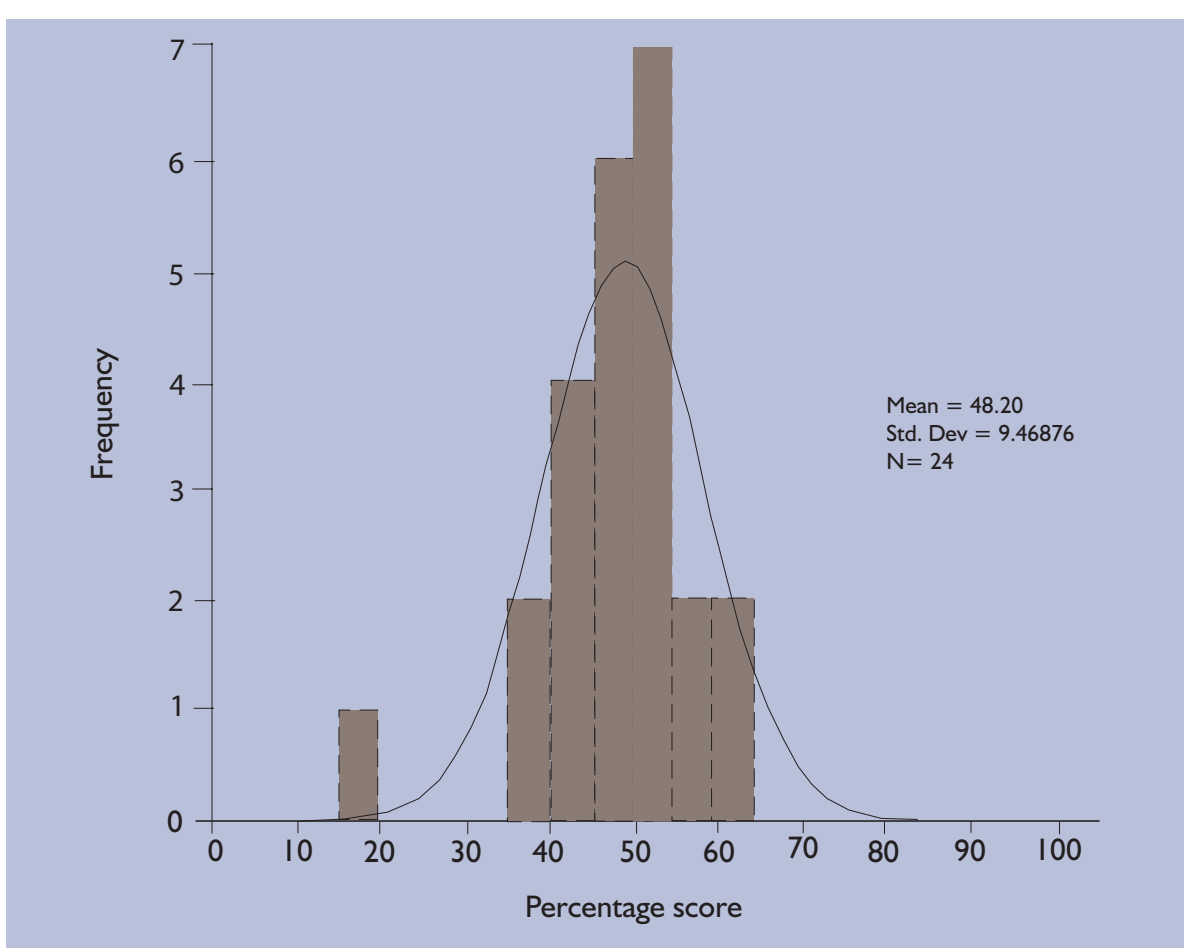

Fig. 5 Histogram showing distribution of mean percentage morale scores for Northern Irish VDPs

training schemes had graduated from one of that country's dental schools - England 90\%, Wales 60\%, Scotland $80 \%$ and N. Ireland $88 \%$.

Non-parametric bi-variate correlations identified no statistically significant correlation between morale scores and the total number of dentists in a practice, or between age and morale scores. Although the VDPs' ages ranged from 21 to 48, 89\% of VDPs were within the range of 23 to 27 years of age.

The scores recorded for each of the individual statements were also examined. The statements associated with the lowest mean score and therefore lowest morale were statement 3: 'I am worried about future changes to NHS dentistry' (mean score 1.84; sd 0.88), and statement 15: 'The current NHS system limits the 
Table 4 The mean Likert scores (S.D.) recorded for each statement by VDPs from each of the four countries surveyed (n. s. = no significant difference). Letters indicate statistically similar subsets within rows

\begin{tabular}{|c|c|c|c|c|c|c|c|c|c|c|}
\hline \multirow{2}{*}{ Statement } & \multicolumn{2}{|c|}{ England } & \multicolumn{2}{|l|}{ Wales } & \multicolumn{2}{|c|}{ N. Ireland } & \multicolumn{2}{|c|}{ Scotland } & \multicolumn{2}{|l|}{ ALL } \\
\hline & $3.15 a$ & $(1.07)$ & $3.00 a$ & (1.14) & $3.42 a$ & (0.89) & $4.09 b$ & (1.10) & 3.28 & (1.10) \\
\hline 2 & $2.94 a$ & (1.02) & $2.81 a$ & (1.08) & $3.17 a b$ & (1.13) & $3.53 b$ & $(0.82)$ & 3.02 & (1.05) \\
\hline 3 n.s. & 1.80 & $(0.86)$ & 1.96 & (0.95) & 1.83 & (0.89) & 1.94 & (1.13) & 1.84 & (0.88) \\
\hline 4 & $2.59 a$ & $(1.05)$ & $2.72 a b$ & (1.19) & $2.83 a b$ & (1.12) & $3.24 b$ & (1.13) & 2.70 & (1.10) \\
\hline 5 & $2.20 a$ & $(0.90)$ & 2.06a & (0.84) & $2.08 a$ & $(1.03)$ & $2.76 b$ & (0.88) & 2.26 & (0.93) \\
\hline 6 n.s. & 3.17 & $(0.90)$ & 3.30 & (0.93) & 3.29 & (0.91) & 3.49 & $(1.20)$ & 3.23 & (0.92) \\
\hline 7 n.s. & 4.47 & $(0.72)$ & 4.43 & (0.88) & 4.33 & (0.66) & 4.49 & $(0.82)$ & 4.47 & (0.73) \\
\hline 8 & $2.52 a$ & (1.05) & $2.32 a$ & (1.02) & $3.38 b$ & $(1.02)$ & $3.60 b$ & $(0.77)$ & 2.69 & (1.11) \\
\hline 9 & $2.67 a$ & $(1.06)$ & $2.96 a b$ & $(1.12)$ & $3.25 b c$ & (0.97) & $3.72 c$ & $(0.99)$ & 2.85 & (1.11) \\
\hline 10 & $2.09 a$ & $(1.01)$ & 2.06a & (0.96) & $2.96 b$ & $(1.02)$ & $3.44 b$ & $(1.00)$ & 2.31 & (1.11) \\
\hline 11 n.s. & 2.53 & (1.03) & 2.83 & $(1.03)$ & 2.79 & (1.16) & 2.88 & $(0.83)$ & 2.61 & (1.05) \\
\hline 12 & $2.87 a$ & $(1.02)$ & $2.74 a$ & (1.11) & $2.92 a b$ & (1.11) & $3.45 b$ & (1.25) & 2.94 & (1.07) \\
\hline 13 n.s. & 2.48 & (0.92) & 2.62 & $(1.05)$ & 2.67 & $(1.00)$ & 2.94 & (0.96) & 2.56 & (0.95) \\
\hline 14 & $2.79 a$ & $(1.10)$ & $2.91 a$ & $(1.06)$ & $2.92 a$ & $(1.01)$ & $3.64 b$ & (0.97) & 2.92 & (1.11) \\
\hline 15 n.s. & 1.83 & $(0.87)$ & 1.94 & (0.96) & 1.83 & (0.91) & 1.98 & (0.92) & 1.86 & (0.89) \\
\hline 16 & $2.44 a$ & (0.95) & $2.40 a$ & $(0.92)$ & $2.92 a b$ & (0.96) & $3.26 b$ & $(0.97)$ & 2.57 & (0.99) \\
\hline 17 & $2.62 a b$ & $(0.97)$ & $2.55 a$ & (1.16) & $2.92 b$ & (0.92) & $3.14 b$ & (0.97) & 2.70 & (0.96) \\
\hline 18 & $2.60 a$ & $(0.95)$ & $2.43 a$ & $(0.83)$ & $3.21 b$ & (0.91) & $3.28 b$ & (0.78) & 2.70 & (0.96) \\
\hline
\end{tabular}

treatment I can offer' (mean score 1.86; sd 0.89). The highest score was associated with statement 7: 'I have good working relationships within my training practice' (mean score 4.47; sd 0.73). Within each region, the highest and lowest scores were associated with these same statements. Statement 1 elicited a positive mean Likert score ( $>3$ ) from each country's VDPs but using one-way Anova and post hoc Scheffé tests, the mean score from Scottish VDPs was significantly higher ( $p$ $<0.001$ ). Table 4 shows the mean scores for each question from each of the four countries. Significant differences could be observed in the mean Likert scores for 12 of the statements in the questionnaire which indicates where the overall differences between the total scores from each country arose.

\section{DISCUSSION}

The contentment or otherwise of professionals at work has been assessed previously by assessing stress ${ }^{15,16}$ (and its consequence, burnout ${ }^{2}$ ), job satisfaction, ${ }^{13,14}$ and to a lesser extent morale. ${ }^{11,18}$ These elements are closely linked. Stress is an important factor affecting job satisfaction, but it is only one of several factors each of which determines job satisfaction to some degree. Similarly, morale is not synonymous with job satisfaction. It is possible to love the type of work that one is doing and yet be demoralised by organisational deficiencies or the lack of rewards, support or recognition etc. Morale and job satisfaction among doctors is reported to be low both in this and other coun$\operatorname{tries}^{18,23}$ and past surveys related changes in job satisfaction to the introduction of new contracts for general medical practitioners. ${ }^{24,25}$ In April 2006, English and Welsh dentists experienced arguably the most fundamental reorganisation of general dental services since the inception of the National Health Service. The higher morale scores seen in this survey among Scottish and Northern Irish VDPs in comparison to their English and Welsh peers might reasonably be attributed to the introduction of the new contract in England and Wales. Indeed, VDPs in England and Wales responded negatively to statements 8 and 10 which relate to the problems which the new contract may cause in finding a suitable practice in which to work; Scottish and Northern Irish VDPs gave significantly more positive responses. Scottish and Northern Irish VDPs were also more positive regarding their value as an NHS dentist, their colleagues' morale and the training opportunities within an NHS practice than the other VDPs. However, the Northern Irish VDPs, who have continued with the previous contractual arrangements, did not respond significantly differently from their English and Welsh counterparts as regards controlling what they could do for their patients, loyalty to the NHS, intention to practise privately, NHS support for career development, or feeling appreciated and rewarded. Although all groups were positive about a future within the NHS and still looking forward to work, 
there was universal concern about future NHS changes, the limits on treatment from the current NHS system and earning enough.

The methodology of this survey allowed a high response rate to be reached and the results can therefore be assumed to give a reliable indicator of the level of morale of this cohort of VDPs as they become independent practitioners (although there is only a small group of VDPs in Northern Ireland). As young professionals finish their training and embark on their careers it is to be hoped that they are optimistic and positive about starting their career. It is therefore surprising and rather worrying to find such low levels of morale among all the UK VDPs. Only in Scotland did the majority attain mean morale scores over 50\% while in England and Wales a greater proportion had morale below $50 \%$. The results presented here suggest that the NHS is viewed negatively by the next generation of English and Welsh dentists while Scottish VDPs generally responded more positively to all the statements than any of the other VDP groups. In a study by Simoens et al., ${ }^{26}$ significantly higher job satisfaction was identified among Scottish GPs compared with English GPs, but this was not present after controlling for demographic, job and practice characteristics. Therefore, although the differences in morale observed between the regions could be due to the introduction of the new contract, it must be recognised that there are also other differences between the regions as regards the organisation and funding of health care, the patient population, and even among the VDPs themselves that have not been considered. Additionally, there is no previous study with which to compare our results to see if morale levels have changed following the new contract's introduction, or whether these regional trends existed in the past. Having now developed a suitable measure for the morale of VDPs, a further survey of this type can be carried out to answer these questions. Nevertheless, this widespread low level of morale among young dentists needs to be addressed if the NHS is to achieve its stated third principle of improving staff morale in order to become a model employer, ${ }^{7}$ and for an effective NHS dental service to continue.

\section{CONCLUSIONS}

The use of an appropriately tested questionnaire has provided a convenient objective measure of morale. The morale of VDPs in each of the four countries of the UK is lower than expected. Scottish VDPs recorded a significantly higher morale score than other VDPs and responded more positively to the statements in the survey instrument. All VDPs responded negatively regarding the effect of the NHS system on treatment and were concerned about future changes to the NHS.

The authors would like to thank Louise Nash $V T$ Adviser in Bristol for her help with the pilot questionnaires and Joy Gittus for the data input and support with this project.

1. Oxford English Dictionary, 2nd ed. Oxford: Clarendon Press, 1989

2. Garland B. Prison treatment staff burnout: consequences, causes, and prevention. Corrections Today 2002; 64: 116-121.

3. Evans L. Teacher morale: an individual perspective. Educ Stud 1992; 18: 161-171.

4. Koeske G, Kirk S. The effect of characteristics of human service workers on subsequent morale and turnover. Adm Soc Work 1995; 19: 15-31.

5. Abbott J. Does employee satisfaction matter? A study to determine whether low employee morale affects customer satisfaction and profits in the business-to-business sector. J Communication
Management 2003; 7: 333-339.

6. Firth L, Mellor D, Moore K, Loquet C. How can managers reduce employee intention to quit? J Management Psychol 2004; 10: 170-187.

7. Department of Health. Improving staff morale webpage. www.dh.gov.uk/en/Policyandguidance/ Humanresourcesandtraining/Improvingstaff morale/index.htm

8. McBride M, Metcalfe D. General practitioners' low morale: reasons and solutions. Br J Gen Pract 1995; 45: 227-229.

9. Grieve S. Measuring morale - does practice area deprivation affect doctors' well-being? Br J Gen Pract 1997: 47: 547-552.

10. Huby G, Gerry M, McKinstry B et al. Morale among general practitioners: qualitative study exploring relations between partnership arrangements, personal style, and workload. BrMed J 2002; 325: 140-145.

11. Gilliland $A E$, Sinclair $H$, Cupples M E, McSweeney $M$, MacAuley D, O'Dowd T C. Stress and morale in general practice: a comparison of two health care systems. Br J Gen Pract 1998; 48: 1663-1667.

12. Handysides S. Enriching careers in general practice: morale in general practice: is change the problem or the solution? Br Med J 1994; 308: 32.

13. Gilmour J, Stewardson D A, Shugars D A, Burke F J. An assessment of career satisfaction among a group of general dental practitioners in Staffordshire. Br Dent J 2005; 198: 701-704.

14. Luzzi L, Spencer A J, Jones K, Teusner D. Job satisfaction of registered dental practitioners. Aust Dent J 2005; 50: 179-185.

15. Wilson $R$ et al. Perceived sources of occupational stress in general dental practitioners. Br Dent $J$ 1998; 10: 499-502.

16. Frazer M. Contributing factors and symptoms of stress in dental practice. BrDent J 1992; 173: 111

17. National Health Service Act 1977: Primary Care Trust Dental Services Directions 2006.

18. Dowell A C, Coster G, Maffey C. Morale in general practice: crisis and solutions. NZ Med J 2002; 115: U102.

19. Linz S, Good L, Huddleston P. Worker morale in Russia: an exploratory study. J Management Psychol 2006: 21: 415-437.

20. Eisenberger R, Cummings J, Armeli S, Lynch P. Perceived organizational support, discretionary treatment, and job satisfaction. J Appl Psychol 1997: 82: 812-820.

21. Cronbach L. Coefficient alpha and the internal structure of tests. Psychometrika 1951; 16: 297-333.

22. Bland J, Altman D. Statistics notes: Cronbach's alpha. Br Med J 1997; 314: 572

23. Steiger B. Survey results: doctors say morale is hurting. Physician Exec 2006; 32: 6-15.

24. Sutherland V J, Cooper C L. Job stress, satisfaction, and mental health among general practitioners before and after introduction of new contract. Br Med J 1992; 304: 1545-1548.

25. Whalley D, Bojke C, Gravelle H, Sibbald B. GP job satisfaction in view of contract reform: a national survey. Br J Gen Pract 2006; 56: 87-92.

26. Simoens S, Scott A, Sibbald B, Bojke C, Gravelle H. Job satisfaction, intentions to quit, and the retention of GPs in England and Scotland. Scot Med J 2002; 47: 80-86. 


\section{Appendix 1 Morale questionnaire used in this survey}

This anonymous questionnaire aims to assess morale among Vocational Dental Practitioners

Please enteryour AGE

your SEX F $\square \quad M \square$

your dental school

In which VT scheme are you?

How many other dentists work at your practice?

For the statements below, please indicate whether you strongly agree (SA), agree (A), ARE neutral (N), disagree (D) OR strongly disagree (SD) with each of the statements by circling the appropriate response

Your answers should reflect the situation where you are currently working

\begin{tabular}{|c|c|c|c|c|c|c|}
\hline 1 & I believe I have a future working in the NHS & SA & A & N & D & SD \\
\hline 2 & I feel valued as an NHS dentist & SA & A & $\mathrm{N}$ & D & SD \\
\hline 3 & I am worried about future changes to NHS dentistry & SA & A & N & D & SD \\
\hline 4 & I don't feel I am able to control what I can do for my patients & SA & A & N & D & SD \\
\hline 5 & The Department of Health has provided sufficient information to reassure me about working in the NHS & SA & A & N & D & SD \\
\hline 6 & I don't look forward to work like I used to & SA & A & N & D & SD \\
\hline 7 & I have good working relationships within my training practice & SA & A & N & D & SD \\
\hline 8 & I will have no difficulty finding a job in a practice I like & SA & A & N & D & SD \\
\hline 9 & Morale is low among my dental colleagues & SA & A & N & D & SD \\
\hline 10 & I worry that I will not be able to work in the area/place I would like & SA & A & $\mathrm{N}$ & D & SD \\
\hline 11 & I am confident that I will earn enough in the NHS & SA & A & N & D & SD \\
\hline 12 & I feel little loyalty to the NHS & SA & A & $\mathrm{N}$ & D & SD \\
\hline 13 & I think the job will be very stressful for me & SA & A & N & D & SD \\
\hline 14 & I intend to work in private practice as soon as possible & SA & A & N & D & SD \\
\hline 15 & The current NHS system limits the treatment I can offer & SA & A & N & D & SD \\
\hline 16 & The NHS will support and encourage my career development & SA & A & N & D & SD \\
\hline 17 & My good work is not appreciated or rewarded & SA & A & $\mathrm{N}$ & D & SD \\
\hline 18 & There will be ample opportunity for training and expanding my experiencein an NHS practice & SA & A & $\mathrm{N}$ & D & SD \\
\hline
\end{tabular}

